\title{
AD SUUM PRINCIPIUM: O CONCEITO DE MULTITUDO EM ESPINOSA ${ }^{1}$
}

\begin{abstract}
Antônio David ${ }^{2}$
Resumo: Objetivamos examinar a centralidade do conceito de multitudo e, por conseguinte, do Tratado Politico para a compreensão da maneira pela qual Espinosa concebe a gênese e a manutenção da vida comum. Para tanto, argumentamos haver no tratado três camadas do conceito de multitudo. A maneira como essas camadas se relacionam é uma chave de interpretação da vida comum e da história em Espinosa.

Palavras-chave: Espinosa - Multitudo - Princípio - Instituição - Ordenação.

Se a razão postula que cada um ame a si mesmo e busque o seu útil3; se os homens levam uma vida que se rege por tudo menos pela razão ${ }^{4}$, se não podem coibir os afetos ${ }^{5}$ e se são sobretudo conduzidos pelo apetite irracional 6 ; se, ademais, os homens são por natureza invejosos, ou seja, regozijam-se diante da debilidade de seus iguais e, inversamente, entristecem-se por causa da virtude deles 7 ; se, finalmente, todos são impedimento uns para os outros, uma vez que todos apetecem por natureza que os outros vivam conforme seu próprio engenho ${ }^{8}$, então de que maneira

1 Esse artigo é uma versão modificada do capítulo 1 da segunda parte de nossa tese de doutorado (FERREIRA, Sui Juris, Fortunae Juris. Ensaio sobre Ontologia e História em Espinosa, 2018). Para efeito de citação da obra de Espinosa, utilizamos as siglas convencionadas entre os comentadores de Espinosa: 1) para o Tratado Político, a sigla "TP”, seguida do capítulo e do parágrafo; 2) para a Ética, a sigla "E”, seguida do livro e da referência; 3) para o Tratado Teológico-Político, a sigla "TTP”, seguida do capítulo e da página na edição consultada; 4) para o Tratado da Emenda do Intelecto, a sigla "TIE" seguida do parágrafo; 5) para os Pensamentos Metafísicos, a sigla "CM", seguida do livro e capítulo; 6) para as cartas, a sigla "Ep.", seguida do número de referência. Os trechos citados podem ter sofrido modificações de tradução em relação à edição consultada. Optamos por não traduzir os vocábulos imperium, multitudo, civitas e conatus. Em relação aos vocábulos e expressões indicados entre colchetes em latim, optamos por mantê-los declinados, tal como se encontram no trecho citado.

${ }^{2}$ Doutor em filosofia pela USP

${ }^{3}$ E, IV, P 18, Esc.; TP, VII, 4; VII, 8; VIII, 24.

${ }^{4}$ TTP, IV, p. 67.

${ }^{5} \mathrm{E}, \mathrm{IV}, \mathrm{P} 17$, Esc. 2.

6 TP, II, 18.

${ }^{7}$ E, III, P 24, Esc.; III, P 32, Esc.; III P 55, Esc..

${ }^{8}$ E, III, P 31, Esc.; IV, P 37, Esc. 1. e Esc. 2. ; IV, P 4, Esc..
\end{abstract}


é possível haver a sociedade historicamente constituída? Antes até, e indo ao limite, se os homens chegam a ser por natureza inimigos9 e esforçam-se o quanto podem por oprimir-se uns aos outros $^{10}$, como é possível originar-se e manter-se a vida em sociedade sem que nela subsista uma situação de permanente hostilidade? Enfim, que alternativa oferece Espinosa para explicar a gênese da sociedade face à quimera e à sátira que nos filósofos encontramos ${ }^{11}$ ?

À luz da tradição, tais questões não seriam problemáticas não fosse o fato de os homens nada poderem menos do que moderar seus apetites ${ }^{12}$, de a religião pouco valer perante os afetos 13 e de, consequentemente, os homens conduzirem-se mais pelo afeto que pela razão14. O que tem Espinosa a oferecer - sobretudo quando se leva em conta que, para ele, o direito natural não é suprimido no estado civil, mas nele vige ${ }^{15}$ - que não uma sociedade de homens aprisionados à inveja, ao ódio, à avareza, à concupiscência etc., pelo qual nenhuma vida social parece ser concebível senão, nas palavras de Hobbes, uma vida "solitária, pobre, sórdida, embrutecida e curta"16? E, no entanto, mesmo aqueles que vivem "na barbárie e sem organização política [barbare sine politica]" e, por isso, "levam uma vida miserável e quase de animais", só conseguem "o pouco que têm, por miserável e rude que seja, através de trabalhos mútuos [mutua opera], seja de que tipo for" ${ }^{17}$. Como conceber semelhante cooperação?

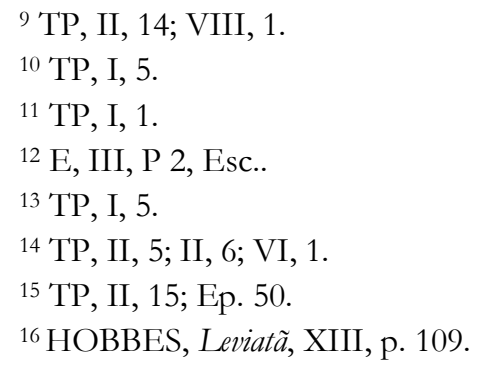

${ }^{17}$ TTP, V, p. 85. Não encontramos nos comentadores menção a essa passagem do Tratado Teológico-Político. Espinosa não explicita quais seriam os que "vivem na barbárie e sem organização política", ao contrário de Hobbes, que, empregando o vocábulo "selvagem", cita nominalmente os povos da América como um caso exemplar de uma vida "solitária, pobre, sórdida, embrutecida e curta": "os povos selvagens [savage people] de muitos lugares da América, com exceção do governo de pequenas famílias, cuja concórdia depende da concupiscência natural [natural lust], não possuem qualquer espécie de governo, e vivem em nossos dias daquela maneira embrutecida que acima referi. Seja como for, é fácil conceber qual seria o gênero de vida quando não havia poder comum a recear, através do gênero de vida em que os homens que anteriormente viveram sob um governo pacifico costumam deixar-se cair, numa guerra civil" (HOBBES, Leviatã, XIII, p. 109-10). No Tratado Teológico-Político, lemos que "os homens, a menos que sejam bárbaros por completo [prorsus barbar], não toleram ser tão abertamente enganados e que os façam baixar de súditos a escravos inúteis" (TTP, XVII, p. 255.). Por sua vez, no Tratado Político, é dito que "os homens, com efeito, uma vez em paz e abandonado o medo, de bárbaros $<\mathrm{e}>$ ferozes [ferocibus $<e t>$ barbaris] fazem-se a pouco e pouco cidadãos, ou seja, humanos [civiles seu bumani], e de humanos fazem-se moles e inertes, não procurando distinguir-se uns dos outros pela virtude mas pelo fausto do luxo. A partir daí, começam a aborrecer-se com os costumes pátrios e a adotar os alheios, ou seja, a ser servos" (TP, X 4). Nas demais obras o vocábulo não aparece. À luz dessas passagens, nas quais barbarus é, no plano ético, contraposto a humano 
Nesse artigo, objetivamos examinar a maneira pela qual Espinosa concebe a gênese e a manutenção da vida em comum. Para tanto, embora em nosso percurso passaremos por várias obras, nosso foco será o Tratado Político. Nele, procuraremos observar o sentido e o lugar do conceito de multitudo, chave para a compreensão não apenas da questão aqui posta, como também da história.

\section{A gênese da vida comum: da Ética ao Tratado Político.}

Na Ética, são poucas as passagens dedicadas à gênese da vida comum. No escólio da proposição IV, P 35, argumenta Espinosa que, a despeito da raridade da vida sob a conduta da razão, os homens "dificilmente podem passar a vida no isolamento [solitudo], de modo que a quase todos agrada bastante aquela definição de que o homem é um animal social", que "da sociedade comum dos homens se originam muito mais comodidades do que danos", e que, a despeito do que dizem os satíricos, os teólogos e os melancólicos, "os homens, com o auxílio mútuo [mutuo auxilio], podem prover-se muito mais facilmente das coisas de que precisam, e só com as forças reunidas podem evitar os perigos que em toda parte os ameaçam" ${ }^{18}$. Claro está que essa explicação é insuficiente. É no escólio 2 da proposição IV, 37 que a gênese da sociedade é efetivamente abordada:

No apêndice da primeira parte, prometi explicar o que são o louvor e o vitupério, o mérito e o pecado, o justo e o injusto. No que tange o louvor e o vitupério, expliquei-os no escólio da proposição 29 da parte III; quanto aos restantes, será

e, no plano político, associado a deixar-se escravizar, é duvidoso que Espinosa tivesse em mente os povos da América. Ademais, há que se lembrar do episódio no qual, face aos acontecimentos de 1672 em Haia, quando os irmãos de Witt foram assassinados e seus corpos foram mutilados e expostos, Espinosa teria escrito um cartaz com os dizeres ultimi barbarorum ("os últimos dos bárbaros"), com o intuito de pregá-lo em algum local próximo dos corpos, o que não se sucedeu porque foi impedido por um hóspede da pensão onde morava (apud DOMINGUEZ, Biografías de Spinoza, 1995, p. 199). Levando em conta todos esses elementos e situando-os no conjunto da obra de Espinosa, podemos concluir que o emprego do termo barbarus cumpre, em verdade, uma função retórica. Ao mesmo tempo, a afirmação de que "todos os homens, sejam bárbaros ou cultos [sive Barbari sive culti], onde quer que se juntem formam costumes [consuetudines] um estado civil [status civilem]" (TP, I, 7) - considerando que, para os homens do seiscentos, "bárbaro" remete aos povos das Américas - faz um relativo contraponto à ideia, divulgada por cronistas e missionários na América Portuguesa, de que, pela ausência das letras "f", "l" e "r" na língua falada na costa brasileira, esses povos não tinham "nem Fé, nem Lei, nem Rei" (cf. GANDAVO, História da Provincia de Santa Crur Do Gentio, p. 122; HANSEN, Vieira e os estilos cultos: "ut theologia rhetorica", 2011, p. 31). Interessanos especialmente o argumento de que todos os homens formam costumes e um estado civil. Em suma, comparado a outros autores, inclusive muito posteriores a ele, Espinosa concebe "estado civil" de maneira mais ampla, como designação de vida em comum.

${ }^{18}$ E, IV, P 35, Esc.. 
este o lugar de falar deles. Mas antes cumpre dizer umas poucas palavras sobre o estado natural e o estado civil do homem. Cada um existe por sumo direito de natureza e, consequentemente, por sumo direito de natureza faz (age) aquilo que segue da necessidade de sua natureza; e por isso por sumo direito de natureza cada um julga o que é bom, o que é mau, e cuida do que lhe tem utilidade conforme seu engenho (ver prop. 19 e 20 desta parte), vinga-se (ver corol. 2 da prop. 40 da parte III) e esforça-se para conservar o que ama e destruir o que odeia (ver prop. 28 da parte III). E se os homens vivessem sob a condução da razão, cada um possuiria (pelo corol. 1 da prop. 35 desta parte) este seu direito sem nenhum dano para outro. Porém, como estão submetidos aos afetos (pelo corol. da prop. 4 desta parte), que de longe superam a potência ou virtude humana (pela prop. 6 desta parte), por isso frequentemente são arrastados [trahuntur] em direções diversas (pela prop. 33 desta parte), e são contrários uns aos outros [invicem] (pela prop. 34 desta parte) enquanto precisam de auxílio mútuo [mutuo auxilio] (pelo esc. da prop. 35 desta parte). Portanto, para que os homens possam viver em concórdia [concorditer] e auxiliar uns aos outros, é necessário que cedam seu direito natural e tornem uns aos outros seguros de que nada haverão de fazer que possa causar dano a outro. Mas de que maneira pode ocorrer que os homens, que são necessariamente submetidos aos afetos (pelo corol. da prop. 4 desta parte), inconstantes e variáveis (pela prop. 33 desta parte), possam tornar seguros uns aos outros e ter confiança uns nos outros, é patente pela proposição 7 desta parte e pela proposição 39 da parte III. $A$ saber, nenbum afeto pode ser coibido a não ser por um afeto mais forte e contrário ao afeto a ser coibido, e cada um abstém-se de causar dano por temor de um dano maior. É portanto por esta lei [lege] que a Sociedade poderá firmar-se, desde que reivindique para si o direito que cada um tem de se vingar e de julgar sobre o bem e o mal; e por isso tenha o poder de prescrever uma regra comum de vida [communem vivendi rationem], de fazer leis e firmá-las não pela razão, que não pode coibir os afetos (pelo esc. da prop. 17 desta parte), mas por ameaças. E esta Sociedade, que se firma pelas leis e pelo poder de se conservar, é denominada Civitas e aqueles que são defendidos pelo direito dela, Cidadãos. Disso facilmente inteligimos que nada é dado no estado natural que seja bom ou mau pelo consenso de todos, visto que cada um que está no estado natural cuida apenas do que lhe tem utilidade, e discerne o que é bom ou mau por seu engenho e enquanto tem por princípio apenas sua utilidade, e por nenhuma lei é obrigado a obedecer a ninguém senão a si mesmo. Por isso não pode ser concebido o pecado no estado natural, mas certamente no estado Civil, onde o que é bom ou mau é discernido pelo consenso comum [communi consensu $]$ e cada um tem que obedecer à Civitas. Portanto, o pecado não é nada 
outro que a desobediência, a qual por conseguinte é punida só pelo direito da Civitas e, inversamente, a obediência é creditada ao Cidadão como mérito, porque por esse motivo é julgado digno aquele que goza das comodidades da Civitas. Ademais, no estado natural ninguém é Senhor de coisa alguma por consenso comum [ex communi consensu], nem na Natureza é dado algo que possa ser dito deste homem e não daquele, mas tudo é de todos; e por isso no estado natural não pode ser concebida nenhuma vontade de atribuir a cada um o que é seu ou de arrancar de alguém o que é seu, isto é, nada pode ser dito justo ou injusto no estado natural, mas certamente no estado civil, onde o que é deste ou daquele é discernido pelo consenso comum [ex communi consensu]. Disso transparece que o justo e o injusto, o pecado e o mérito são noções extrínsecas, e não atributos que expliquem a natureza da Mente. Mas basta sobre isso ${ }^{19}$.

Não examinaremos aqui todos os pontos que julgamos merecer exame; alguns serão mais adiante abordados. Por ora, chamamos a atenção para dois pontos. Em primeiro lugar, já nessa passagem Espinosa oferece a resposta às indagações com que abrimos o presente artigo: cada um abstém-se de causar dano aos demais por temor de um dano contrário e mais forte, o que é possível (a rigor, necessário) porque um afeto só é coibido por outro afeto contrário e mais forte. Note-se que Espinosa dá para isso o nome de "lei", e que dela a razão não participa. No Tratado TeológicoPolítico, ele explica que essa lei "está tão firmemente inscrita na natureza humana que temos que colocá-las entre aquelas verdades eternas que ninguém pode ignorar", a saber, que ninguém despreza o que considera ser bom, a não ser na esperança de um maior bem ou por receio de um maior dano, nem aceite um mal a não ser para evitar outro ainda pior ou na esperança de um maior bem; em suma, entre dois bens, escolhe-se aquele que se julga ser o maior, e entre dois males, o que pareça menor ${ }^{20}$.

Em segundo lugar, não é casual o emprego, três vezes, da expressão communi consensu na passagem citada. Na Epistola 32, Espinosa mostra que, na relação entre as partes e o todo, opera a oposição entre inter se consentire e inter se discrepare: as coisas são partes de um todo sempre e quando suas naturezas ajustam-se reciprocamente de maneira a, na medida do possível, entre si concordarem; inversamente, sempre que discrepam, cada uma das partes já é considerada como um todo e não mais como parte. Sabemos que consensus e consentire compreendem ambos a mesma família lexical. Da mesma maneira que as partículas que coexistem no sangue, porque concordam entre si, constituem todas simultaneamente [simul omnes constituant] um só fluido, também os indivíduos constituem um só corpo ex communi consensu, "por consenso comum". O emprego do vocábulo consensus evidencia não se tratar de um consentimento fraco, atualizado em cada situação

${ }^{19} \mathrm{E}, \mathrm{IV}, \mathrm{P} 37$, Esc. 2, o destaque é nosso.

${ }^{20}$ TTP, XVI, p. 237-8. 
de escolha, e que pode ter lugar como pode não ter lugar, mas de um recíproco ajustamento da qual tem lugar um só corpo, porque lastreia-se ontologicamente, está "inscrita na natureza humana" 21.

Uma espécie de síntese do escólio encontra-se nos capítulos 26 a 28 do Apêndice do Livro IV da Ética. Diz o Capítulo 26 que, além dos homens, não conhecemos na natureza nada de singular cuja mente possa nos regozijar e a que possamos nos unir por amizade ou algum outro gênero de relação [amicitia, aut aliquo consuetudinis genere]. Já o Capítulo 27 anuncia a utilidade das coisas que existem fora de nós "principalmente para a conservação do corpo", e que "as coisas mais úteis são aquelas que podem alentar e nutrir o corpo para que todas as suas partes consigam cumprir corretamente suas funções"; ainda esse mesmo capítulo informa que parece haver poucas coisas deste tipo na natureza, quando é preciso usar muitos alimentos de natureza diversa para nutrir o corpo, que precisa de alimento contínuo e variado. Finalmente, o Capítulo 28 sustenta que, com vistas à reunião dessas coisas, as forças de cada um dificilmente bastariam se os homens não prestassem trabalhos mútuos [operas mutuas]"22. A leitura conjunta dos três capítulos mostra a centralidade do homem para a mente (capítulo 26), de um lado, e das coisas externas para o corpo (capítulo 27), de outro, cuja reunião depende da cooperação (capítulo 28). Em ambos os casos, converge-se para a ideia de que nada há mais útil ao homem que o próprio homem ${ }^{23}$.

Não obstante a Ética e a Epistola 32 ofereçam um quadro conceitual imprescindível à compreensão da gênese da vida comum em Espinosa, resta uma lacuna, que a leitura dessas duas obras deixa em aberto: a sociedade é a mera soma de indivíduos? Julgamos que essa questão resta em aberto, mesmo à luz da parte do Livro II da Ética denominada "pequena física" 24 . A nosso juízo, essa lacuna será preenchida somente pelo Tratado Político, obra por excelência dedicada à questão da gênese do direito comum.

Pelo exercício de comparação entre as passagens há pouco examinadas e o que encontramos no Tratado Politico, salta aos olhos de imediato a ausência, naquelas, do conceito-chave com o qual Espinosa opera no tratado. Enquanto na Ética figuram na gênese da vida em comum "cada um", "o homem" e "os homens", no Tratado Politico, por sua vez, o centro do palco é ocupado pela multitudo. Para se ter dimensão da inovação trazida pela última obra de Espinosa, basta dizer que a multitudo sequer aparece na Ética25 e que, embora figure no Tratado Teológico-Político, sua ocorrência se dá em poucas as passagens e sem semelhante protagonismo ${ }^{26}$.

\footnotetext{
${ }^{21}$ Quanto a isso, vale notar a etimologia do vocábulo consensus: con (junto) + sensus (sentir, perceber).

${ }^{22}$ E, IV, Ap., Cap. 26, 27 e 28.

${ }^{23}$ E, III, P 18, Esc.; IV, P 35, Cor. 1.

${ }^{24}$ Por nós examinada no capítulo 2 da primeira parte de nossa tese. Cf. FERREIRA, Sui Juris, Fortunae Juris. Ensaio sobre Ontologia e História em Espinosa, 2018, p. 41-67.

${ }^{25}$ Não no sentido que lhe é atribuído no Tratado Político. Na Ética, em uma passagem Espinosa emprega a expressão "multiplicidade de causas" [multitudine causarum] (E, V, P 20, Esc.). Nos Pensamentos Metafísicos, por sua vez, o termo multitudo é empregado em oposição a unitas (“unidade”) (CM, I, 6). Embora fiel, a tradução de multitudo por multiplicidade carece, assim pensamos, de literalidade. A quase totalidade dos comentadores traduz multitudo por "multidão". Julgamos que essa opção é válida em alguns contextos, mas não em todas,
} 
Para dar conta da lacuna apontada, com vistas à explicação da gênese da vida comum em Espinosa, nosso percurso terá na multitudo seu ponto de apoio e referência. Em verdade, procuraremos extrair da obra um conceito de multitudo - pois Espinosa em nenhum momento a define explicitamente. Com isso, pretendemos que explicação e conceituação andem pari passo, um jogando luz sobre o outro.

\section{Principium, institutum, ordenatio: as três camadas do conceito}

Para a construção do conceito de multitudo, pensamos que não convém seguir a ordem de exposição do Tratado Politico. Sustentamos haver, na obra, três camadas argumentativas em torno do conceito de mulitudo, que, todavia, não obedecem a qualquer ordem expositiva, mas se entrelaçam e se misturam no decorrer dos capítulos. Cada uma delas é polarizada - e por isso podemos distinguilas - por um conceito-chave, quais sejam, princípio [principium], instituição [institutum] e ordenação [ordenatio] ${ }^{27}$. Passaremos por cada uma dessas camadas para, ao cabo, mostrarmos como articulamse e formam, em conjunto, um conceito coerente de multitudo.

Comecemos pela primeira camada, o principium. De início, e para que se observe com maior nitidez a diferença com que a gênese da vida comum é abordada no Tratado Político e na Ética, convém examinar os parágrafos II, 15, 16 e 17 do Tratado Politico. É nesse último parágrafo que a multitudo é pela primeira vez introduzida no tratado.

No parágrafo II, 15, Espinosa afirma a nulidade do direito natural de um só no estado natural, onde seria em vão o esforço realizado por cada um para precaver-se de todos, e, inversamente, a validade do direito natural de cada um no estado civil, onde os homens têm direitos comuns [jura communia], do que conclui: "quantos mais forem os que assim se põem de acordo [conveninunt], mais direito têm todos juntos" 28 . Já no parágrafo II, 16, nosso autor sustenta que onde os homens têm direitos comuns [jura communia] e todos são conduzidos como que por uma só mente [una veluti mente ducuntur], é certo que cada um deles tem tanto menos direito quanto os restantes juntos são mais potentes [potentes] que ele, ou seja, não tem realmente sobre a natureza nenhum direito para além daquele que o direito comum [commune jus] the concede29. Com base nessas considerações, o parágrafo II, 17 define o direito comum e nomeia quem o detém:

como procurarmos mostrar, e dada a conotação, no mundo contemporâneo, da palavra "multidão" e seus correspondentes em outros idiomas, optamos por manter o vocábulo em latim.

${ }^{26}$ No Tratado Teológico-Político, figuram sobejamente os conceitos de populo e de plebs. Sobre a razão dessa diferença entre os dois tratados, mencionaremos adiante.

${ }^{27}$ Não é desnecessário lembrar que a distinção entre camadas não é um conceito que figura na obra, sendo antes um recurso analítico que empregamos e que a realidade é uma só e a mesma, não havendo camada alguma no real.

28 TP, II, 15.

${ }^{29}$ TP, II, 16, o destaque é nosso. 
Este direito [jus] que se define pela potência da multitudo [multitudinis potentia definitur] costuma [solet] chamar-se Imperium. E detém-no absolutamente [absolute tenet] quem, por consenso comum [ex communi consensu], tem a incumbência da república [curam Reipublicae], ou seja, de estatuir, interpretar e abolir direitos [jura], fortificar as urbes, decidir sobre a guerra e a paz, etc. E se esta incumbência [cura] pertencer a um conselho que é composto pela multitudo comum [communi multitudine], então o imperium chama-se democracia; mas, se for composto só por alguns selecionados [selecti], chama-se aristocracia; e se, finalmente, a incumbência da república [Republicae cura] e, por conseguinte, o imperium estiver nas mãos de um só, então chama-se monarquia ${ }^{30}$.

Esse trecho deve ser examinado com cuidado. Três coisas chamam de pronto a atenção. Em primeiro lugar, a passagem entre os homens tomados isoladamente e a multitudo é marcada pelo contraste entre, de um lado, a potência de um só e a potência de cada um (implicitamente presentes nos parágrafos II, 15 e 16, mas mencionada à exaustão nos parágrafos anteriores) e, de outro, a potência da multitudo 31 . O vocábulo contém conteúdo ontológico, afinal, "poder existir é potência (como é conhecido por si)" 32. Em segundo lugar, o direito comum "é definido" pela potência da multitudo, do que depreendemos, à luz do conceito de "definição"33, que a potência da multitudo pertence à essência mesma do direito comum, sendo, portanto, dela inseparável, sob pena de esse direito ser destruido ${ }^{34}$. Em terceiro lugar, quem "absolutamente detém" esse direito só o detêm "por consenso comum" isto é, à luz da Epistola 32, trata-se esse direito de uma constituição, ou seja, todos os indivíduos constituem simultaneamente um corpo, de modo que esse corpo é mais do que a soma das partes (em sintonia com o que é dito no escólio 2 da proposição IV, P 37) - e detém-no porque têm a "incumbência da República" - o que esvazia tanto a concepção tradicional de monarquia e de aristocracia, pois ambas são incumbências de uma República ${ }^{35}$, como a ideia tradicional de poder absoluto como aquele poder que é separado ou transcendente, mesmo quando assim pareça ser.

\footnotetext{
30 TP, II, 17.

31 Nesse ponto, é marcante a diferença entre Espinosa e Hobbes, para quem, mesmo no estágio da "união", posterior ao "consentimento", o sujeito ainda é "cada um" (cf. HOBBES, Do Cidadão, II, V, 6-7; Leviatã, XVII, p. 141-4).

32 E, I, P 11, Dem., Doutra Maneira.

33 E, III, P 4.

${ }^{34}$ E, II, Def. 2. Daí a razão pela qual, na passagem da Ética há pouco citada, Espinosa argumente que a sociedade se firma "pelas leis e pelo poder de se conservar" (o destaque é nosso). Cf. também TP, III, 9.

35 O que aproxima Espinosa de Maquiavel, que, a nosso juízo, objetivou mostrar n’O Príncipe que o principado só pode ser estável se tiver conteúdo republicano. Note-se, na passagem da Ética sobre a gênese da sociedade, que a cessão do direito de que nela se fala não é absoluta, mas restritiva: a sociedade reivindica para si o direito que cada um tem de certas coisas: "de se vingar e de julgar sobre o bem e o mal".
} 
Note-se que, ao contrário do escólio da Ética há pouco analisado, no parágrafo II, 17 Espinosa não faz menção a afetos. É claro que os afetos estão aqui pressupostos, uma vez que no estado natural a razão para temer é máxima ${ }^{36}$. Todavia, o ponto para o qual queremos chamar a atenção da leitura conjunta dos parágrafos II, 15, 16 e 17 é que neles não se confere ao medo a proeminência na constituição do direito comum ${ }^{37}$; esta é conferida à potência da multitudo. Porque o foco aqui é a definição do direito comum, nessa camada aborda-se a gênese da vida em comum fora da duraşão. E não poderia ser de outra maneira, afinal, não há passagem do estado natural ao estado civil: em primeiro lugar, a civitas nunca é dissolvida ${ }^{38}$, de modo que, rigorosamente falando, não há estado natural historicamente constituído, e em toda parte e sempre, onde há homens, há estado civil; em segundo lugar, e em contrapartida, o direito natural vige no estado civil e só nele é válido ${ }^{39}$ (com tudo o que dissemos nos parágrafos iniciais deste capítulo).

No início do capítulo II, o mesmo do qual extraímos as citações que ora analisamos, ao explicar a ligação e, a bem dizer, a dependência da potência das coisas naturais em relação à potência de Deus, Espinosa afirmara que "o princípio da existência das coisas naturais, tal como a sua perseverança na existência, não pode concluir-se de sua definição", e conclui, depois de resumir argumentos já expostos na Ética e dos quais tratamos na primeira parte, que "a potência pela qual as coisas naturais existem, e pela qual consequentemente operam, não pode ser nenhuma outra senão a própria potência eterna de Deus" ${ }^{40}$.

À luz da teoria espinosana do conatus $^{41}$, sabemos que o princípio da existência da multitudo é imanente a ela e, assim sendo, em se tratando do direito comum, a presença desse princípio merece com toda propriedade ser designado por conatus comum, a despeito de esse conceito não figurar na obra. Assim, quando dizemos que a multitudo tem a potência ou o direito, é ao conatus comum que nos reportamos.

Ilumina-se, com isso, algumas afirmações presentes no Tratado Político. Por exemplo, que todos os homens, sejam por bárbaros ou cultos, formam um estado civil42; que os homens, quer sejam conduzidos pela razão, quer não sejam - sabemos que a maioria não é -, ao fundarem um imperium, visam ao máximo aquilo que, no estado natural, ainda que em vão, se esforçaria cada um dos que conduzem pela razão43; e que na civitas os homens não perdem a natureza humana e adquirem uma outra ${ }^{44}$. Ilumina-se também o sentido da afirmação de que a finalidade do imperium

\footnotetext{
36 TP, II, 14-5.

${ }^{37}$ Inversamente a Hobbes. Cf. HOBBES, Do Cidadão, V, 4.

38 TP, VI, 2.

39 TP, II, 15; Ep. 50.

40 TP, II, 1.

${ }^{41}$ Cf. CHAUI, Politica em Espinosa, 2003, p. 128 s.

42 TP, I, 7.

43 TP, VI, 1, o destaque é nosso.

44 TP, IV, 4.
} 
civil 45 é garantir a paz e a segurança. Essa finalidade não é transcendente, mas imanente; não é uma meta visada, mas a própria "lei universal" inscrita na natureza humana segundo a qual entre dois males, vale o menor, e entre dois bens, vale o maior.

Passemos à segunda camada, o institutum. Preliminarmente, é necessário observar a maneira como o conatus comum intervém na duração. Consideramos que a passagem que melhor joga luz sobre essa questão é a seguinte:

Dado que os homens, como dissemos, se conduzem mais pelo afeto que pela razão, segue-se que não é por condução da razão [ex rationi ductu], mas por algum afeto comum [ex aliquo communi affectu] que a multitudo se põe naturalmente de acordo [naturaliter convenire] e quer ser conduzida como que por uma só mente [uni veluti mente duci velle], ou seja (como dissemos no art. 9, cap. III), por uma esperança ou medo comuns, ou pelo desejo de vingar algum dano comum ${ }^{46}$.

A presença do conatus comum na duração transparece em dois argumentos presentes na passagem que acabamos de ler, a saber, a conveniência a partir de "algum afeto comum", de um lado, e que nesse momento a multitudo "quer ser conduzida como que por uma só mente".

Ao leitor do Tratado Político, a expressão "conduzida como que por uma só mente" é familiar ${ }^{47}$. No que consiste essa ideia? Na Ética, lemos que a razão pela qual nada há mais útil ao homem que o homem é "nada haver que os homens possam escolher de preferível para conservar o seu ser do que convir todos em tudo [omnes in omnibus conveniant]" de maneira tal que as mentes e os corpos de todos "componham [componant como que uma só mente e um só corpo", e que "todos simultaneamente [simu], o quanto possam, se esforcem para conservar o seu ser, e que todos busquem simultaneamente [simul para si o útil comum a todos [omninum commune utile] ${ }^{48}$. A presença da teoria exposta na Epistola 32 é patente. Assim, na Ética e na referida carta, temos o referencial teórico adequado que nos permite compreender, sem espaço para mistério, o sentido da expressão. Mas persiste uma questão: por que só nessa passagem somos informados que a multitudo "quer ser" conduzida como que por uma só mente?

O parágrafo III, 8 oferece um dado importante. Uma vez tendo definido "estado civil" como estado de qualquer imperium ${ }^{49}$, Espinosa acrescenta ser o estado civil "naturalmente instituído [instituitur] para eliminar o medo comum e afastar as comuns misérias, visando ao máximo àquilo por que, no estado natural, ainda que em vão, se esforçaria cada um dos que conduzem pela razão".

\footnotetext{
$45 \mathrm{TP}, \mathrm{V}, 2$.

46 TP, VI, 1, o destaque é nosso.

47 TP, II, 16; III, 2; III, 5; III, 7; VIII, 8; VIII, 19.

${ }_{48} \mathrm{E}, \mathrm{IV}, \mathrm{P} 18$, Esc..

49 TP, III, 1, o destaque é nosso.
} 
A passagem em questão, em torno da instituição natural do estado civil, situa-se em um ponto do argumento no qual Espinosa afirma não ser o estado civil contrário à razão, posto que a sã razão [sana ratio], não ensinando nada contra a natureza, "não pode ditar que cada um permaneça sob o senhorio de si mesmo [sui juris] quando os homens estão submetidos aos afetos", mas, ao contrário, "ensina inteiramente a procurar a paz, a qual não pode obter-se a não ser que os direitos comuns da civitas permaneçam inviolados" ${ }_{50}$. Se, como há pouco vimos, os homens se põem de acordo "por algum afeto comum" e não por condução da razão, essa conveniência não se contrapõe à razão, antes está de acordo com ela.

A isso acrescente-se o que é dito no parágrafo III, 2. Após ter apresentado os conceitos fundamentais da política, lemos:

Do art. 15 do capítulo anterior resulta claro que o direito do imperium ou das potestades supremas [imperii seu summarum potestatum Jus] não é senão o próprio direito de natureza [naturae Jus], o qual se determina [determinatur] pela poltência, não já de cada um, mas da multitudo [multitudinis], que é conduzida como que por uma só mente [quae una veluti mente ducitur]; ou seja, da mesma forma que cada um no estado natural, o corpo e a mente de todo o imperium têm tanto direito quanto vale a sua potência. E assim, cada um, cidadão ou súdito, tem tanto menos direito quanto a própria civitas é mais potente que ele (ver art. 16 do capitulo ant.), e consequentemente cada cidadão não faz ou possui por direito [jure] nada a não ser aquilo que pode defender por decreto comum da cidade [communi Civitatis decreto] $]^{51}$.

A comparação entre essa passagem e o parágrafo II, 17, o primeiro a ser examinado no tópico anterior dedicado ao principium, evidencia a razão de a Ética ter dito que a multitudo "quer ser". No capítulo II, mencionava-se apenas a potência da multitudo; no capítulo III, fala-se de uma potência conduzida (como que por uma só mente). No primeiro, a potência da multitudo define o direito; no segundo, ela o determina (limita). Lá, detém absolutamente o direito comum on o imperium quem, por consenso comum, tem a incumbência da República; aqui, o direito se diz "do imperium ou das potestades supremas". O que há efetivamente de novo nessas passagens em relação às anteriores é precisamente a presença das potestades supremas, funções concretas na civitas, cujo poder é por ela (de)limitado.

A passagem entre querer ser e efetivamente ser (a rigor, como que ser) conduzida por uma só mente demarca, assim pensamos, a fronteira entre o conatus comum, ontológico, e o ato (político) de instituição do imperium e sua organização (jurídica), histórico. O termo instituto é abundantemente

50 TP, III, 6.
51 TP, III, 2. 
empregado no Tratado Politico e designa tanto a fundação do imperium (direito comum) ${ }^{52}$ como sua continuação na duração. Pelo Tratado Teológico-Político sabemos que a instituição, frequentemente associada à lei, ao hábito e ao imperium, opõe-se à verdade eterna e à natureza - das coisas se diz que ou são "por instituição" ou são "por natureza" 53. Essa indicação é importante, haja vista o termo figurar apenas duas vezes na Ética ${ }^{4}$. Ela informa que o terreno da instituição é a duração e que sua atuação, por assim dizer, se dá sob circunstâncias históricas determinadas.

$\mathrm{Na}$ abertura do Tratado Político, imediatamente após a crítica aos filósofos, de que tratamos na Introdução, Espinosa aborda aqueles que, de certa forma, situam-se no polo contrário: os homens práticos, no que se incluem os políticos:

[...] os direitos comuns [jura communia] e os assuntos públicos [negotia publica] foram instituídos [instituta] e tratados por homens agudíssimos, quer astutos, quer hábeis, e por isso é difícil acreditar que possamos conceber alguma coisa aplicável [ex usu] a uma sociedade comum [communi Societati] que a ocasião [occasio] ou o acaso [casus] não tivessem já mostrado e que os homens atentos aos assuntos comuns [communibus negotiis] e ciosos de sua própria segurança não tivessem visto55.

O esforço de Espinosa no curso do Tratado Político é para mostrar que a instituição, enquanto fundação, condiciona a posterior situação do imperium ${ }^{56}$. Não surpreende que, logo na sequência dessa última citação, Espinosa evoque Maquiavel, que teria mostrado os meios de que um príncipe deve usar para dominar (isto é, em face de uma multitudo subjugada), os meios que de que a multitudo livre deve se valer para resguardar sua liberdade, e a imprudência de uma multitudo que retira o tirano, mas não a causa da tirania (causa essa que remonta à fundação do imperium).

Espinosa oferece como exemplo dessa imprudência da multitudo o episódio que foi a razão próxima que o levou a escrever o Tratado Político: o golpe de Estado de 1672 que destituiu e assassinou os irmãos de Witt, aboliu a República e reinstaurou a dinastia da Casa de Orange nas Sete Províncias do Norte. Diz Espinosa sobre esse período, em alusão à instauração da República anos antes, que "os holandeses julgaram que para obter a liberdade era suficiente afastar o conde e decapitar o corpo do imperium, e não pensaram em reformá-lo [reformando]" 57 . A questão da mudança de forma será matéria do capítulo X do Tratado Político.

\footnotetext{
52 TP, III, 1.

${ }^{53}$ TTP, IV, p. 71, 73-4; V, p. 81; XVI, Anotação XXXIV, p. 246. Assim, quando na obra se fala em "direito e instituição de natureza”, fala-se da potência de uma essência singular (TP, II, 8; TTP, XVI, p. 234, 236).

${ }^{54}$ Cf. nota dos tradutores da Ética, p. 587.

55 TP, I, 2.

56 Tese que havia sido sustentada antes por Maquiavel. Cf. MAQUIAVEL, Discursos sobre a primeira década de Tito Livio, I, 2.

57 TP, IX, 14. Cf. BALIBAR, Spinoza et la politique, 2005, p. 26s.; BALIBAR, Ultimi Barbarorum - Espinoza: 0 temor das massas, 1990.
} 
Para que se depreenda o caráter determinante da instituição, é útil examinarmos os parágrafos V, 5 e 6, nos quais Espinosa aborda o melhor imperium, a saber, aquele no qual os homens passam a vida em concórdia e que se define acima de tudo pela razão. Segundo nosso autor, o imperium instituído para esse fim é aquele que a multitudo livre [multitudo libera] institui, e não aquele que se adquire sobre a multitudo por direito de guerra [jure belli], e complementa:

Porque a multitudo livre [libera multitudo] é conduzida mais pela esperança do que pelo medo, ao passo que uma multitudo subjugada é conduzida mais pelo medo do que pela esperança: aquela procura cultivar a vida [vitam colere], esta procura somente [tantummodo] evitar a morte [mortem vitare]; aquela, sublinho, procura viver para si, esta é obrigada a ser do vencedor, e daí dizermos que esta é serva [servire] e aquela é livre [libera]. Assim, o fim [finis] do imperium de que alguém se apodera por direito de guerra [Jure belli] é dominar e ter servos em vez de súditos. E embora entre o imperium que é criado pela multitudo livre [libera multitudine creatur] e aquele que é adquirido por direito de guerra [juri belli acquiritur], se atendermos genericamente ao direito [jus] de cada um, não haja nenhuma diferença essencial [essentialis], contudo, quer o fim, como já mostramos, quer os meios com os quais cada um deles se deve conservar [conservar] têm enormes diferenças ${ }^{58}$.

Operando com a clivagem instituição versus aquisição, a passagem parece limitar-se a operar no campo do que a tradição designa por jus belli, o direito de guerra ${ }^{59}$. Todavia, essa é uma visão superficial da passagem. Uma leitura atenta do Tratado Politico faz transparecer, pelo emprego do conceito de "guerra" [bellum], que a questão não se limita à aquisição de uma civitas por outra. No curso do tratado, Espinosa refere-se a imperia e civitate nos quais, apesar de não terem sido conquistados, vivem sob a vigência da jus belli e, como tais, são assim caracterizados. Se assim for, a passagem inevitavelmente enseja a seguinte questão: o que faz de uma multitudo livre, e outra serva? A pergunta a essa questão só poderá ser satisfatoriamente respondida mediante o exame da terceira camada, a ordenatio, e a consequente conjugação das três camadas.

Passemos, finalmente, à terceira camada, a ordenatio. Uma vez introduzido no imperium a autoridade, a determinação do direito do imperium ou das potestades supremas pela multitudo é qualificada: esse lugar é ocupado por todos (democracia), por poucos (aristocracia) ou por um só (monarquia). A rigor, ou por todos ou por poucos, porque nenhum homem é capaz de sozinho sustentar um imperium, de modo que, adverte Espinosa, toda monarquia é, na verdade, uma aristocracia tácita ${ }^{60}$. Com essa advertência, pode-se conjecturar que Espinosa tenha seguido a trilha

${ }^{58} \mathrm{TP}, \mathrm{V}, 6$.

${ }^{59}$ Cf. BOVE, Direito de guerra e direito comum na politica espinosista, 2008.

60 TP, VI, 5. "Estão, sem dúvida, muito enganados os que creem que pode acontecer um sozinho obter o direito supremo da civitas. O direito, efetivamente, determina-se só pela potência, como mostramos no 
deixada por Maquiavel quanto ao conflito fundamental, em todas as civitate, entre povo e grandes ${ }^{61}$, muito embora multitudo e povo não se sobreponham perfeitamente, como procuraremos argumentar.

Diversamente da incumbência da República, que consiste em um lugar e designa o próprio direito comum mediado pelo consenso comum, as potestades supremas consistem em funções concretas, ocupadas por pessoas singulares, e designam a detenção de um direito jurídico. Para que se retenha a diferença, cumpre notar que, enquanto o direito definido pela potência da multitudo, o qual se costuma chamar imperium, é a própria potência da multitudo, já o direito das potestades supremas é o direito do imperium: é, portanto, um direito (jurídico) de um direito (natural). E porque se tratam de homens, e não de quaisquer homens, mas de autoridades, esse direito jurídico que as autoridades detêm é determinado (limitado, freado) pela potência da multitudo.

$\mathrm{Na}$ leitura do Tratado Politico, saltam aos olhos as razões pelas quais o poder das autoridades deva ser freado. Além de todos os apontamentos feitos na obra sobre a natureza humana - que o direito se estende até onde se estende a potência ${ }^{62}$, que procurar igualdade entre desiguais é coisa absurda63, que não se deve depositar na palavra dada a segurança do imperium ${ }^{64}$ e todas as considerações feitas na abertura do presente capítulo -, vale acrescentar o que é dito no prefácio do Tratado Teológico-Político em relação ao direito das potestades supremas, a saber, que "muitos se esforçam, com descarado atrevimento, por lhes usurpar em boa parte" 65 .

É nessa camada, ao tematizar a transferência do direito, que se deve situar a expressão integra multitudo, tal como exposta no capítulo VII:

É, além disso, certo que cada um prefere governar a ser governado. Ninguém, com efeito, concede voluntariamente o imperium a outrem, conforme diz Salústio no primeiro discurso a César. É, por isso, claro que a multitudo intacta [multitude integra] nunca transferiria [transferet] o seu direito para uns poucos, ou para um só, se

capítulo II, e a potência de um só homem é, de longe, incapaz de sustentar tão grande peso. Daí acontecer que aquele a quem a multitudo elege rei chama para junto de si comandantes, conselheiros e amigos, aos quais confia a sua salvação e a de todos, de tal modo que o imperium, que se crê ser abertamente monárquico, na prática [in praxi], é realmente aristocrático, não de modo manifesto [manifestum], mas latente [latens], e por isso mesmo péssimo" (TP, VI, 5). A expressão “incapaz de sustentar tão grande peso" faz alusão à passagem bíblica na qual Moisés queixa-se a Deus de sua incapacidade de sustentar o peso do povo (Nm 11:10-17).

61 “.... em todas as [civitate], existem esses dois humores diversos que nascem da seguinte razão: o povo não quer ser comandado nem oprimido pelos grandes, enquanto os grandes desejam comandar e oprimir o povo; desses dois apetites diferentes, nascem nas cidades um destes três efeitos: principado, liberdade ou licença" (MAQUIAVEL, O Principe, IX, p. 43).

62 TP, II, 4; II, 5; VII, 16.

63 TP, IX, 4.

64 TP, II, 12; TP, XI, 2.

${ }_{65}$ TTP, Pref., p. 8-9. 
pudesse pôr-se de acordo entre si [inter impam convenire possit] e se das controvérsias [controversiis $]$ que tão frequentemente se desencadeiam nos grandes conselhos [in magnis consiliiis] não se passasse à sedição [seditiones] ${ }^{66}$.

A passagem chama a atenção pelo que nela é implicitamente negado: "se pudesse pôr-se de acordo entre si [inter impam convenire possit]". Ora, como vimos em outra passagem do próprio Tratado Político, a multitudo pode pôr-se de acordo entre si. Ocorre que, no capítulo VI, quando afirmara que por algum afeto comum a multitudo se põe naturalmente de acordo [naturaliter convenire] e quer ser conduzida como que por uma só mente, era do principium que se falava. Aqui, a presença das controvérsias nos grandes conselhos demarca um campo social e político no qual a divisão social tem lugar, face à qual vislumbra-se uma alteração - daí, como contraposição, a expressão integra multitudo.

Se, escreve Espinosa na sequência, a multitudo "só transfere livremente para um rei aquilo que é absolutamente impossível ela própria ter em seu poder, ou seja, o dirimir as controvérsias e o decidir com rapidez" ${ }^{67}$, cabe notar que essas duas incumbências - vale lembrar, diversas daquelas de que se falava na primeira camada, fundadas na Natureza - já nascem sob o manto da divisão social. Em uma palavra, a diferenciação social nascida no interior mesmo da multitudo constrange-a a incorrer na transferência de direito.

Para melhor compreender por que é enfraquecida a aptidão da multitudo para se colocar de acordo, é necessário observar dois aspectos dessa camada para o qual Espinosa dá ênfase particularmente nos dois tratados: de um lado, o fato de na multitudo ecoar, por assim dizer, a natureza dos indivíduos que a compõem ${ }^{68}$; de outro, o fato de multitudo "ser conduzida", em particular nos imperia aristocrático e monárquico. Quanto a esse segundo ponto, lemos no Tratado Teológico-Político não haver nada mais eficaz que a superstição para governar as multitudines, que muitos se esforçam por usurpar os direitos das potestades supremas tentando, a pretexto da religião, pôr contra elas o ânimo das multitudines [multitudinis animum] ${ }^{69}$ e que, nas controvérsias, levanta-se contra o rival a fúria da multitudo ${ }^{70}$. Já quanto ao primeiro ponto, diz Espinosa:

\footnotetext{
66 TP, VII, 5. Diogo Pires Aurélio, Charles Ramond e D’Émile Saisset optaram por traduzir integra por "inteira". Paolo Cristofolini, por seu turno, optou por "compacta". Já Atilano Dominguez empregou "completa". De nossa parte, pensamos que a tradução que melhor se ajusta ao conceito nesse contexto é "intacta”, tanto por remeter a uma situação originária como por conotar aquilo que ainda não sofreu violação. 67 TP, VII, 5.

68 “[...] as causas e fundamentos naturais do imperium [imperia causas \& fundamenta naturalia] não devem pedir-se aos ensinamentos da razão, mas deduzir-se da natureza ou condição comum dos homens [hominum communi natura, seu conditione]" (TP, I, 7).

${ }^{69}$ TTP, Pref., p. 7-9. Cf. também TP, VIII, 41: "não há de fato nada que mais comova os ânimos da multitudo [multitudinis animos movet]".

70 TTP, XVIII, p. 283.
} 
Que a manutenção do imperium depende, antes de mais nada, da fidelidade dos súditos, da sua virtude e da sua perseverança na execução das ordens, a razão e a experiência ensinam-no sem margem para dúvidas. Descobrir, porém, o modo como eles devem ser governados para que mantenham sempre a fidelidade e a virtude já não é assim tão fácil. Todos, com efeito, sejam governantes ou governados, são homens, que o mesmo é dizer, têm tendência para fugir à labuta e procurar o prazer [ex labore scilicet proclives ad libidinem]. Aqueles que sabem a qual ponto é mutável o engenho das multitudines [varium multitudines ingenium] quase que desespera de o descobrir: porque a multitudo não se rege pela razão, rege-se pelas paixões, tudo a atrai e deixa-se facilmente corromper, seja pela avareza, seja pelo luxo. Cada qual julga que só ele sabe tudo e quer que tudo seja orientado segundo a sua maneira de ver; conforme pensa que uma coisa lhe tratá lucro ou prejuízo, assim a considera justa ou iníqua, legítima ou ilegítima; por amor à glória, despreza os seus semelhantes e não suporta ser governado por eles; por inveja de um título mais elevado, ou da fortuna, que nunca está igualmente repartida, deseja o mal a outrem e sente prazer nisso; nem vale a pena prosseguir, uma vez que ninguém ignora a que crimes o descontentamento pela sua condição presente e o desejo de novas coisas, a cólera arrebatada, o desprezo pela pobreza, inspiram frequentemente aos homens e quanto essas paixões lhes invadem e agitam os ânimos. Obviar pois, a todos esses males, instituir um imperium em que não haja lugar para a fraude, instituir tudo, em suma, de maneira que todos, seja qual for o seu engenho, ponham o direito público à frente de seus interesses privados [omnia ita instituere, ut omnes, cujuscunque ingenii sint, jus publicum privatis commodis praeferan円], aí é que está a obra, o trabalho a fazer ${ }^{71}$.

Desses dois elementos, quais sejam, a condição comum dos homens imanente à natureza da multitudo e a superstição como instrumento de dominação através do governo da multitudo, o segundo equivale a um reforço ou a um maior enraizamento da primeira ${ }^{72}$. Esse reforço, vale notar, ocorre simultaneamente à diferenciação social que se dá em seu interior: Não poderia ser de outra maneira, afinal, é de seu interior não como potência, como integra multitudo, mas como pluralidade na duração, que surgem tanto os patrícios (na aristocracia) como as famílias, a nobreza e o rei (na monarquia) ${ }^{73}$.

\footnotetext{
71 TTP, XVII, p. 253.

${ }^{72}$ Cf. FERREIRA, Sui Juris, Fortunae Juris. Ensaio sobre Ontologia e História em Espinosa, 2018, p. 52.

${ }^{73}$ TP, VI, 11-3; VIII, 1.
} 


\section{Multitudo e história}

É somente à luz das três camadas, vistas em conjunto, que se pode interpretar os capítulos finais do Tratado Politico: aqueles dedicados à monarquia (capítulos VI e VII) e à aristocracia (capítulos VIII e IX), bem como o capítulo que trata centralmente da mudança de forma dos imperia (capítulo $\mathrm{X}$ ) e o inacabado capítulo dedicado à democracia, do qual temos apenas os quatro primeiros parágrafos (capítulo XI). Neles as três camadas como que se combinam, criando um campo ontológico de coexistência entre direito natural e direito civil que torna perceptivel e inteligivel o campo de conflitos, negociações e disputas, no qual a história transcorre. Para o nosso intento no presente artigo, e por economia, é suficiente determo-nos sobre o capítulo X. Antes, porém, cabe examinarmos o emprego dos conceitos de forma, facies e fabrica no Tratado Político.

No capítulo VI, Espinosa já havia alertado que das discórdias e sedições que muitas vezes são provocadas na civitas, nunca resulta que os cidadãos a dissolvam, como muitas vezes acontece nas restantes sociedades: "mudam-lhe, sim, a forma [formam] por uma outra, se as contendas [contentiones] não puderem ser acalmadas [sedari] mantendo a face da civitas [Civitatis facie]". Conclui Espinosa: "por meios que se requerem para conservar o imperium, eu entendo os que são necessários para conservar a forma [formam] do imperium sem alguma mudança digna de nota" 74 . As discórdias e sedições serão abordadas com maior atenção no capítulo 3. O que nos interessa por ora é o argumento da mudança ou conservação da forma.

A fim de melhor precisar o conceito, pensamos ser útil compará-lo a outros dois: "face" [facies] e "estrutura" [fabrica]. Para tanto, atentemos para alguns argumentos dispostos ao longo do Tratado Político. Segundo Espinosa, os imperia aristocrático e monárquico diferem, entre outras coisas, no fato de que o primeiro não torna à multitudo, diferentemente do segundo ${ }^{75}$. Ademais, a escolha do rei, que é feita pela multitudo, deve, se possível, ser eterna - caso contrário acontecerá necessariamente de a potestade suprema transitar muitas vezes para a multitudo, que é a maior e a mais perigosa das mudanças -, e cuja primeira linha anuncia que "a face do imperium [imperii facies] deve manter-se una e idêntica", do que conclui que o rei deva ser um só, sempre do mesmo sexo, e o imperium deva ser indivisível ${ }^{76}$. Em outra passagem na qual aborda os dois imperia, Espinosa argumenta que quanto maior é o direito da suprema potestade, mais a forma do imperium [imperii forma] é conforme ao que dita a razão e, consequentemente, mais apta é para conservar a paz e a liberdade" "77. Ao evocar aqui o argumento da forma do imperium, Espinosa remete ao parágrafo III, 5 , pela qual na civitas o corpo do imperium deve ser conduzido como que por uma só mente e, por conseguinte, a vontade da civitas deve ter-se por vontade de todos e ser considerada como se fosse

\footnotetext{
74 TP, VI, 2.

75 TP, VIII, 1.

76 TP, VII, 25.

77 TP, VIII, 7.
} 
decretada por cada um ${ }^{78}$. E, ao discorrer sobre a atribuição do conselho na aristocracia - mas o mesmo vale para a monarquia -, Espinosa assevera que "quem tenha, nem que seja por um só dia, o poder de criar e abrogar leis, esse pode mudar toda a forma do estado [imperii formam]" 79 .

Em relação especificamente à monarquia, no parágrafo VII, 26 somos informados de que, naquele capítulo e no anterior, considerava-se o imperium monárquico que uma multitudo livre instituiu, único a que podem aplicar-se os fundamentos ali elencados, e que uma multitudo que se habitou a outra forma de imperium [imperii formae] não poderia, sem grande perigo de desabamento [eversione], remover os fundamentos de todo o imperium e mudar toda a sua estrutura [fabricam] ${ }^{80}$. Por sua vez, no parágrafo VII, 30 Espinosa afirma, em relação aos capítulos VI e VII, tratar-se ali da "melhor forma [formam optimam] de imperium monárquico, se quisermos considerar as causas da conservação de qualquer imperium não bárbaro e as do seu desabamento [eversionis]" 81 .

No que toca à aristocracia, ao tratar no parágrafo VIII, 13 da proporção numérica entre patrícios e o restante, Espinosa argumenta que "o número de patrícios pode ser muito maior que o da multitudo e a forma do imperium [imperii forma] conservar-se", e que o perigo residiria na sua escassez ${ }^{82}$. No parágrafo seguinte, Espinosa sustenta repugnar à "forma deste imperium [imperii formae]" a dignidade patrícia ser hereditária, pois um imperium assim mais parece um democrático tal como antes descrito, quando fizera menção à desigualdade entre cidadãos e estrangeiros ${ }^{83}$. Tomando-se as devidas precauções em relação à proporção, nesse caso "preservar-se-á a forma do imperium [imperii forma] e poderá sempre conservar-se a proporção entre patrícios e multitudo".

Feitas essas considerações, que conteúdo podemos dar ao conceito de "forma" e no que esse conceito difere de "face" e "estrutura"? Pela Ética, sabemos que fabricam remete à natureza enquanto considerada apenas corpórea ou em seu aspecto estritamente físico ${ }^{84}$. Em vista disso, e em vista do que é dito no parágrafo VI, 19, a saber, que o rei é como a mente e o conselho é como corpo do imperium, a mencionada mudança de estrutura - que, ao lado da remoção dos "fundamentos recebidos", levaria ao desabamento do imperium - parece referir-se às instituições singulares. Nossa hipótese é de que, para intervir nas instituições do imperium sem grave perigo, a condição para tanto é que a multitudo tenha potência; todavia, uma multitudo que não é habituada à liberdade é impotente para tanto.

Por sua vez, o que depreendemos dessas passagens sobre o termo "face"? Por que na primeira citação é dito que a face da civitas não muda mesmo com a mudança da forma do imperium, ao passo que na segunda citação é dito que a face do imperium deva manter-se una e idêntica - o que

\footnotetext{
78 TP, III, 5.

79 TP, VIII, 17.

80 TP, VII, 26.

81 TP, VII, 30,

82 TP, VIII, 13.

83 TP, VIII, 14.

${ }^{84}$ E, II, P 2, Esc.; IV, P 49, Esc..
} 
pressupõe a possibilidade de mudar? Uma hipótese é que a face designe os traços que caracterizam algo pelo que nele há de exterior e que é percebido pela imaginação. Por que a face da civitas não muda quando há discórdias e sedições nela provocadas? Porque "nunca resulta que os cidadãos a dissolvam, como muitas vezes acontece nas restantes sociedades". Qualquer que seja a forma assumida, o aspecto será o de civitas, o corpo inteiro [integrum corpus] do imperium ${ }^{85}$. E por que a face do imperium deve manter-se una e idêntica? Para que seja reconbecido como um imperium monárquico.

A título de ilustração e exemplo, vale aqui retomar, de um lado, a diferença entre o imperium que é criado pela multitudo livre e aquele que é adquirido por direito de guerra e, de outro, do exemplo das Sete Províncias do Norte, do qual tratamos algumas linhas atrás. Segundo Espinosa, entre o imperium criado pela multitudo livre e aquele que é adquirido por direito de guerra, "se atendermos genericamente [in genere] ao direito de cada um", não veremos nenhuma "diferença essencial [essentialis]", embora efetivamente haja enormes diferenças nos meios e nos fins empregados ${ }^{86}$. Essa generalidade remete à face do imperium. Em relação ao exemplo, "os holandeses julgaram que para obter a liberdade era suficiente afastar o conde e decapitar o corpo do estado, e não pensaram em reformá-lo [eodem reformando]", tendo ficado "qual corpo sem cabeça", do que resultou "deformada situação [deformi statu]" imaginavam estar numa República, porque só para o corpo olhavam, quando "aqueles que realmente detinham o imperium eram, de longe, menos que os que poderiam governar a multitudo e dominar adversários potentes". Tendo face de República, as Sete Províncias na verdade eram uma aristocracia (tácita).

Todas as indicações a respeito da forma, ao lado do que acabamos de afirmar em torno dos conceitos de face e de estrutura, indicam que, enquanto a face e a estrutura remetem ao corpo político (a primeira correspondendo ao aspecto externo pelo qual é reconhecido e a segunda às instituições singulares), a forma corresponde à mente do imperium. É digno de nota que, no parágrafo VII, 26, Espinosa não diga, em contraposição a uma multitudo que se habituou a outra forma de imperium, que ali considerava o imperium instituído por uma multitudo habituada à

\footnotetext{
85 TP, III, 1.

$86 \mathrm{TP}, \mathrm{V}, 6$.

87 "E se alguém retorquir que este imperium dos holandeses não aguentou muito tempo sem um conde, ou um substituto que fizesse as vezes dele, terá por resposta que os holandeses julgaram que para obter a liberdade era suficiente afastar o conde e decapitar o corpo do estado, e não pensaram em reformá-lo, deixando todos os seus membros tal como antes estavam constituídos, de tal maneira que o condado da Holanda ficou sem conde, qual corpo sem cabeça, e o próprio imperium ficou sem nome. Não é por isso de admirar que a maioria dos súditos ignorasse em que mãos estava o poder soberano. E ainda que não fosse assim, aqueles que realmente detinham o imperium eram, de longe, menos que os que poderiam governar a multitudo e dominar adversários potentes. Daí que estes tenham, frequente e impunemente, podido conspirar contra eles e, finalmente, depô-los. A súbita queda da sua república não teve, pois, origem no fato de consumirem inutilmente o tempo em deliberações, mas na deformada situação [deformi statu] deste imperium e na escassez de governantes" (TP, X, 14).
} 
monarquia, mas sim que ali considerava o imperium instituído por uma multitudo livre. Ao empregar o termo forma no Tratado Político, Espinosa designa a liberdade ou a servidão da mente. Assim, se as formas dos imperia aristocrático e monárquico são as que foram deduzidas nos capítulos VI a IX e não as que se dão na duração, isso se deve ao fato de o direito comum ser definido pela potência da multitudo conduzida como que por uma só mente. A forma de que Espinosa fala, ao tratar desses dois imperia, é a liberdade, realizada, contudo, de maneira precária, cada qual a sua maneira.

Nesses termos, notamos aqui também o parentesco entre Espinosa e Maquiavel, que na abertura d'O Príncipe declara estarem os domínios formados tal como ele ali descrevera "habituados ou a viver sob um príncipe ou a ser livres" 88 . Espinosa igualmente concebe a política na chave da dicotomia entre favorecimento e desfavorecimento da liberdade. Porém, um e outro não coincidem inteiramente. Em Maquiavel, essa liberdade, como sabemos, é dada pela República, de modo que República e Principado contrapõem-se - muito embora possamos vislumbrar traços republicanos no principado tal como concebido n'O Príncipe. Espinosa não emprega o termo "principado", mas a monarquia e a aristocracia deduzidas da natureza comum desses imperia são chamadas com frequência no tratado de Repúblicas ${ }^{99}$ - mas não livres ${ }^{90}$. São para ele Repúblicas não por outro motivo senão porque, deduzidas de suas naturezas comuns, são consoantes à razão.

Dito isso, podemos finalmente adentrar no capítulo X do Tratado Político. $\mathrm{Na}$ abertura do capítulo, Espinosa informa que uma vez tendo sido apresentados e explicados os fundamentos dos imperia aristocráticos (compreendendo uma só urbe, ou várias urbes), restaria averiguar "se eles podem, por alguma causa que lhes seja imputável [aliqua causa culpabili], dissolver-se ou assumir uma outra forma [aliam formam]" 91 .

O capítulo divide-se em três partes, correspondentes a três argumentos: o ditador como primeiro remédio às doenças que acometem o imperium; a avareza como segundo remédio; a inviolabilidade dos direitos como único meio de garantir a estabilidade do imperium. Não é o caso de examiná-los em pormenor: os argumentos dispostos no segundo já foram evocados por nós e, em relação ao terceiro ponto, dele trataremos nos capítulos seguintes.

O que aqui interessa reter do capítulo é uma ideia fundamental posta no argumento da cura pela ditadura, e que Espinosa extrai de Maquiavel:

A primeira causa por que se dissolvem os imperia deste gênero é aquela que o agudíssimo florentino observa nos Discursos sobre Tito Livio, III, 1, a saber, que ao estado, tal como ao corpo humano, todos os dias se agrega alguma coisa que, de vez. em quando, necessita de cura. Daí que seja necessário, diz ele, que de vez em quando aconteça alguma coisa [accidat] através da qual o imperium seja

\footnotetext{
${ }^{88}$ MAQUIAVEL, O Principe, I, p. 3.

${ }^{89}$ TP, VI, 18; VII, 29; VIII, 3; VIII, 9; VIII, 12; VIII, 24; VIII, 31; VIII, 33; VIII, 49.

${ }^{90}$ Ibidem, VIII, 49.

${ }^{91} \mathrm{TP}, \mathrm{X}, 1$.
} 
reconduzido ao seu principio, onde começou a estabilizar-se [ad suum principium, quo stabiliri incepit, redigatui $]^{92}$.

Essa passagem conjuga o que pretendemos mostrar no presente artigo, sendo, segundo julgamos, uma chave de interpretação do Tratado Politico. Toda a argumentação em torno das três camadas do conceito de multitudo consiste em depreender, ao fim e ao cabo, o sentido da afirmação segundo a qual o imperium é "reconduzido ao seu princípio" por meio de um acontecimento. Examinemos essa afirmação.

Ao cabo da argumentação iniciada com a menção aos Discorsi, e após cogitar que o primeiro remédio pudesse ser a nomeação de um ditador supremo [supremus dictatur] "por um ou dois meses, com direito a investigar, julgar e estatuir sobre o que fazem os senadores e cada um dos funcionários e, consequentemente, restituir o imperium ao seu princípio [ad suum principium restituendi]", Espinosa conclui que tal remédio pode acabar por se converter em veneno, posto que o ditador "pode um dia transformar-se, não sem grande perigo para a república, numa monarquia" 93 .

Tem-se, assim, um impasse: por um lado, para ser efetivo, esse poder ditatorial precisa ser eterno e estável, bem como temível só para os maus, ou seja, não deve deixar espaço para o arbítrio, mas ser guiado pela razão; por outro lado, a manter-se a forma do imperium, esse poder não pode ser conferido a um só. A conclusão é que, para que se obtenha todas essas condições, o "gládio ditatorial" deveria estar nas mãos não de uma pessoa natural [personam naturalem], mas civil [personam civilem $]^{94}$. Remete-se aqui ao arranjo institucional, tal como deduzido nos capítulos do Tratado Político dedicados à monarquia e à aristocracia. A "pessoa civil" é a instituição que garante a proporcionalidade do imperium.

Ora, por que Espinosa dá para isso o nome de "retorno ao princípio"? Afinal, o que a argumentação em torno da ditadura esclarece sobre essa noção? Claro está que, ao falar de "retorno ao princípio", Espinosa tem em mente não a fundação do imperium, pois, obviamente, para um imperium mal ordenado desde sua fundação a "volta ao princípio" nada significaria. Diferente de Maquiavel, em Espinosa o termo principium designa não a fundação - essa é designada pelo termo institutum -, mas a presença da potência de Deus nas coisas naturais. No caso, designa o conatus comum.

\footnotetext{
92 TP, X, 1, o destaque é nosso. No capítulo em questão dos Discorsi, Maquiavel argumenta que "todos os princípios [...] hão de ter em si alguma bondade, pela qual retomem o prestígio e o vigor iniciais", mas que, "com o passar do tempo, essa bondade se corrompe". Argumenta ainda que "esse bem surge nas repúblicas por virtù de um homem ou por virtù de uma ordenação". Ao evocar o princípio, Maquiavel tem em mente a fundação. No mesmo capítulo, é feita menção às "boas constituições, ordenadas por Rômulo e por outros príncipes prudentes" (cf. MAQUIAVEL, Discursos sobre a primeira década de Tito Livio, III, 1).

${ }_{93} \mathrm{TP}, \mathrm{X}, 1$.

${ }^{94} \mathrm{TP}, \mathrm{X}, 1-2$.
} 
O ponto que merece relevo, a essa altura, é que, se no curso da explicação mostramos que a primeira camada situa-se fora da duração, aqui vemos a presença dessa mesma camada na duração. Como vencer aparente contradição?

Em primeiro lugar, do ponto de vista ontológico, ela remete à presença do direito natural no estado civil. Noutros termos, o princípio faz-se presente na instituição ou fundação e na posterior duração ou ordenação de todo e qualquer imperium porque todo e qualquer imperium se define pela potência da multitudo, sem a qual cessa de existir.

Em segundo lugar, cumpre notar que a multitudo não é um conceito unívoco, ao menos não em determinado sentido. É certo que, em determinadas passagens, o conceito é empregado como sinônimo de povo ou mesmo para designar um grupo. A leitura do Tratado Político não dá margem à dúvida quanto a isso. Essa é a multitudo polarizada pelo conceito de ordenação. Mas é igualmente certo, no entanto, que, em determinadas passagens, a multitudo designa um acontecimento político que tem lugar na história, a saber, o conjunto dos indivíduos reunidos no ato de fundação do imperium, designação polarizada pelo conceito de instituição. Da mesma maneira, é certo que, em determinadas passagens, a multitudo designa o conatus comum, um sujeito político ontológico situado fora da duração. Aqui, o conceito é polarizado pela noção de princípio. Em suma, mesmo fora da duração, essa designação da multitudo, polarizada pelo princípio, apesar de situar-se fora da duração, não se situa fora da história95.

Isso aparece com evidência quando observamos situar-se no princípio a definição da estabilidade ou da instabilidade do imperium. Diz Espinosa que o imperium aristocrático "será tanto mais seguro e a sua condição será tanto melhor, quanto maior for, relativamente ao monárquico, a sua proximidade ao absoluto sem prejuízo da paz e da liberdade", pois "quanto maior é o direito da potestade suprema, mais a forma do imperium convém [convenit] com o que dita a rąãa e, por conseguinte, mais apta é para conservar a paz e a liberdade" 96 . Se em um dado imperium, em sua singularidade, os direitos comuns são preservados no direito civil e nas leis, ele será estável e haverá segurança para aqueles que detêm a potestade suprema e paz aos cidadãos. Caso contrário, haverá instabilidade, insegurança e hostilidade:

$\mathrm{Na}$ verdade, se há imperium que pode ser eterno, é necessariamente aquele cujos direitos [jura], uma vez corretamente instituídos, permanecem inviolados. Porque a alma do imperium são os direitos [anima imperii jura sunt]. Mantidos estes, mantém-se necessariamente o imperium. Os direitos, contudo, não podem ser invencíveis a não ser que sejam defendidos não só pela razão, mas também pelo afeto comum dos

\footnotetext{
95 Essa é a razão pela qual multitudo e povo não se sobrepõem perfeitamente, bem como por que, no Tratado Teológico-Político, figuram os conceitos de populo e de plebs ao invés de multitudo.

96 TP, VIII, 7, o destaque é nosso.
} 
homens [communi hominum affectu defendantur]; de outra forma, se estão apoiados só no auxílio da razão, sem dúvida são fracos e vencem-se facilmente ${ }^{97}$.

Se a multitudo, polarizada pelo princípio, não se situa fora da história, a contrapartida é que a história só é inteligível na medida em que as três camadas do conceito de multitudo são observadas ao mesmo tempo. Nesse sentido, e somente nesse sentido, o conceito de multitudo pode ser considerado unívoco ${ }^{98}$. Em outras palavras, a inteligibilidade da história consiste em observar, em cada fenômeno histórico, a maneira particular como operam, de maneira concomitante, o conatus comum ou o desejo de governar e não ser governado (princípio), as heranças e marcas da fundação do imperium (instituição) e os conflitos e divisões no tempo presente (ordenação).

Disso podemos extrair uma hipótese extremamente frutífera para o futuro dos estudos espinosistas: a grande contribuição de Espinosa ao propor o "retorno ao princípio", segundo pensamos, está menos na ideia de um acontecimento, tal como lemos no parágrafo X, 1, do que na ideia, consoante com a vigência do direito natural no estado civil, de uma projeção das três camadas, conjugadas de uma maneira particular, sobre a sociedade historicamente constituída, dando lugar a um campo de conflitos, negociações e disputas capaz de alterar-lhe ou preservar-lhe a face (o aspecto externo), a estrutura (seu arranjo institucional) e a forma (o lugar relativo de uns perante outros, produzindo maior ou menor igualdade entre as partes). Não fosse assim, sequer o acontecimento seria inteligível. Se a hipótese que aqui lançamos proceder, cabe investigar de que maneira a conjugação das três camadas da multitudo se particulariza, dando lugar às sociedades particulares e sua história. Espinosa lançou as bases dessa investigação no Tratado Teológico-Político, quando investigou o imperium hebraico.

\section{AD SUUM PRINCIPIUM: THE CONCEPT OF MULTITUDOIN SPINOZA}

Abstract: Our goal is to examine the centrality of the concept of multitudo and therefore of the Political Treatise for the understandig the way by which Spinoza conceives the genesis and the maintenance of common life. We argue that there are in the treatise three layers on the concept of multitudo. The way by which those layers relate is a key to interpretation of common life and history in Spinoza.

Keywords: Spinoza - Multitudo -Principe -Institution - Ordenation.

\section{Referências Bibliográficas:}

BALIBAR, E. Spinoza et la politique. Paris: Presses Universitaires de France, 2005, 3e édition.

97 TP, X, 9.

98 Nesse sentido, Chaui designa a multitudo como "sujeito político". Cf. CHAUI, Política em Espinosa, 2003, p. 254s. 
."Ultimi Barbarorum - Espinoza: o temor das massas". In: Discurso, nº 18, 1990, p. 7-35.

BOVE, L. "Direito de guerra e direito comum na política espinosista". In: Conatus, vol. 2, no 4, dez. 2008, p. 91-7.

CHAUI, M. Politica em Espinosa. São Paulo: Companhia das Letras, 2003.

DOMINGUEZ, A. (comp.). Biografías de Spinoza. Selección, traducción, introducción, notas e índices por Atilano Domínguez. Madrid: Alianza Editorial, 1995.

ESPINOSA, B. "Carta no 32". Tradução e notas Marilena Chaui. In: Espinosa. Coleção Os Pensadores. São Paulo: Abril Cultural, 1979, $2^{\text {a }}$ edição, p. 367-93.

Ética. Tradução Grupo de Estudos Espinosanos; coordenação Marilena Chaui. São Paulo: Editora da Universidade de São Paulo, 2015.

Princípios de filosofia cartesiana e Pensamentos metafísicos. Tradução Homero Santiago, Luis César Guimarães Oliva. Belo Horizonte: Autêntica, 2015.

Tratado da emenda do intelecto. Tradução Cristiano Novaes de Rezende. Campinas: Editora da Unicamp, 2015.

. Tratado Político. Tradução Diogo Pires Aurélio. São Paulo: Martins Fontes, 2009.

Tratado Teológico-político. Tradução Diogo Pires Aurélio. São Paulo: Martins Fontes, 2003.

FERREIRA, A. M. D. S. Sui Juris, Fortunae Juris. Ensaio sobre Ontologia e História em Espinosa. (Tese de doutorado). Faculdade de Filosofia, Letras e Ciências Humanas, Universidade de São Paulo, 2018.

GANDAVO, P. M. História da Provincia de Santa Cru₹. Organização Ricardo Martins Valle, Introdução e notas Ricardo Martins Valle e Clara Carolina Souza Santos. São Paulo: Hedra, 2008.

HANSEN, J. A. "Vieira e os estilos cultos: ut theologia rhetorica". In: Letras, Santa Maria, vol. 21, $\mathrm{n}^{\circ}$ 43, jul./dez. 2011, p. 25-62.

HOBBES, T. Do Cidadão. Tradução, apresentação e notas Renato Janine Ribeiro. São Paulo: Martins Fontes, 2002, $3^{\mathrm{a}}$ edição.

Leviatã. Tradução: João Paulo Monteiro, Maria Beatriz Nizza da Silva. São Paulo: Editora Nova Cultura, 1999. 
MAQUIAVEL, N. Discursos sobre a primeira década de Tito Livio. Tradução MF. São Paulo: Martins Fontes, 2007.

. O Príncipe. Tradução Maria Júlia Goldwasser. São Paulo: Martins Fontes, 2001.

SPINOZA, B. Opera. Im Auftrag der Heidelberger Akademie der Wissenschaften hrs. von Carl Gebhardt. Heidelberg, C. Winter, 1972.

Traité politique. Traduccion d'Émilie Saisset revisée par Laurant Bove. Introducction et notes par Laurant Bove. Paris : Librairie Générale Française, 2002.

Traité politique. Tradiccion, introduccion, notes, glossaires, index et bibliographie par Charles Ramond. Paris: Presses Universitaires de France, 2005.

- Tratado político. Traducción, introducción, índice analítico y notas de Atilano Domínguez. Madrid: Alianza Editorial, 1986.

Trattato politico. $2^{\text {a }}$ edição. Edizione critica del testo latino e traduzione italiana a cura di Paolo Cristofolini. Firenze: Edizioni ETS, 2011. 